\title{
La imposibilidad del origen: el proceso de re- construcción histórica en Hossein (1955), de Inés Guzmán Arias
}

\author{
Mariana Libertad SUÁREZ y María Beatriz VILLA \\ Universidad Simón Bolívar
}

\begin{abstract}
RESUMEN
Entre 1952 y 1958 una gama de libros de memorias, testimonios y novelas históricas fueron escritos por mujeres venezolanas, con la intención de reeditar algunos eventos pasados desde la distorsión de la contemporaneidad. Por medio de intertextualidades, juegos de anacronismos, parodias y fragmentariedades, en estas obras, la tergiversación de la Historia se tornó una noción indispensable para adquirir un "yo". Así pues, partiendo de este marco, se propone una aproximación a la novela Hossein (1955) de la autora venezolana Inés Guzmán Arias, un texto sumamente importante por su complejidad, su ambigüedad y las paradojas que contiene. En esta obra se replantean las aproximaciones al pasado del siglo XX, a partir de un proceso de autoficcionalización de la autora, quien se erige como traductora o transcriptora de los hechos. Un gesto que le permite a Guzmán Arias, mostrar nuevos sucesos y nuevos sujetos como entes indispensables en la construcción de un pasado colectivo.
\end{abstract}

Palabras clave: Historia, subalternidad, reconstrucción, novela histórica, literatura venezolana.

The impossibility of the origin: the process of historical reconstruction in Hossein (1955), by Inés Guzmán Arias

\begin{abstract}
Between 1952 and 1958 a range of memory books, testimonies and historical novels were written by Venezuelan women, to reissue some of the past's events from the present time's distortion. Through intertextualities, anachronisms, parodies and fragmentation games in these literary works, misrepresentation of history has become an essential notion to acquire a sense of "self". Starting from this scenery, it is expected to comprehend cast back's uses in Venezuela during the fifties, taking the novel Hossein by Inés Guzmán Arias as a starting point, a text with unique importance because of its complexity, ambiguity, and paradox. At the same time, it reconsiders the various approximations to twentieth century's past, from the author's autofiction and from her point of view as a translator of the facts. A gesture that allows Guzmán Arias to show new events as well as new subjects as essential entities for the construction of collective past.
\end{abstract}

Keywords: History, Subordination, Reconstruction, Historic ovel, Venezuelan literature. 
Hablaba pausadamente con voz dulce y franciscana; tenía nariz fina, boca pequeña, labios delgados, prontos siempre a la sonrisa atrayente. Todo en él atraía e inspiraba veneración.

Su color de canela hacía conocer su raza, pero era imposible sondear su origen, tal era el respeto que inspiraba e imponía. Su frente estaba siempre inclinada, sus manos juntas en actitud de estar absorto en una oración ante el altar. Así era, más o menos, el venerable "Padre Joseph", como todos le llamaban (Inés Guzmán Arias, Hossein)

Con la llegada de los años cincuenta del siglo XX, se instauró en Venezuela una larga diatriba en torno a la concepción del pasado. En ese período, la historiografía nacional sufrió un proceso de profesionalización que, casi de inmediato, entró en conflicto con el mapa subjetivo regente en los medios de comunicación social, los ejercicios narrativos canonizados y la reconstrucción histórica de corte nacionalista. Importantes medios de comunicación como la revista Elite, el diario El Heraldo, la Revista Nacional de Cultura e, incluso, en ocasiones el periódico El Nacional sirvieron como plataforma para que estos paradigmas dijeran y desdijeran cuáles eran los sucesos y los sujetos indispensables en la construcción de un pasado colectivo, al tiempo que -con la publicación de estas tensiones- hicieron tambalear las heroicidades labradas por unos y otros esfuerzos de reconstrucción del pasado. En el año 1955, en el No 4.269 del diario El Nacional, el crítico José Nucete Sardi intentaba sintetizar la discusión. Para ello, afirmaba:

\begin{abstract}
Diversos historiadores venezolanos aun conociendo las diferentes escuelas y tendencias historiográficas y diciéndose practicantes de alguna de ellas, no las aplicaron siempre en sus trabajos. En veces estos fueron resultando una narración hilvanada de brillantez, dedicada más a la exaltación de los hechos bélicos que a otros sucesos y situaciones menos brillantes pero esenciales para la formación de la nacionalidad [...] La discusión, el debate sobre historiografía se ha abierto en diversos momentos. La obra de Baralt, por ejemplo, sin que se le restaran los méritos que tiene, dio margen a la crítica para señalarle, desde su aparición, defectos de método y criterio con las disculpas de ambiente y época. Se le impugnó aquel concepto erróneo de que "los trabajos de la paz no dan materia a la historia" y que sólo lo bélico y político son los aspectos interesantes para ella (Nucete Sardi: 1955: 4)
\end{abstract}

Esa mirada conciliadora del crítico, daba cuenta de una serie de desencuentros que ponían en el tapete al menos cuatro temas asociados a la definición del sujeto venezolano durante la década de los cincuenta. Las pugnas entre desarrollismo y tradicionalismo, el origen militar y origen civil, la identidad individual y la identidad colectiva, junto con la imposibilidad de concertar la mirada objetiva y la jerarquización subjetiva de los hechos históricos, develaban la existencia de al menos 
dos proyectos políticos simultáneos y, como consecuencia de ello, de dos grupos de intelectuales orgánicos con un capital simbólico equivalente en la Venezuela de mitad del siglo XX.

Ciertamente, la división más sencilla de estos dos grupos vendría marcada por la aceptación o el rechazo, por parte de los historiadores, del proyecto perezjimenista de nación; sin embargo, la primera aseveración de Nucete Sardi, según la cual los intelectuales venezolanos, aun conociendo y admitiendo como legítimo uno de los paradigmas de conocimiento, contaminaban su escritura con algún otro, constituye una pista interesante para comprender que la reconstrucción del pasado desde una u otra perspectiva no sólo suponía una postura política, sino también una mirada ideológica más compleja.

Tanto los historiadores profesionales como los creadores de novelas históricas o biografías noveladas gozaban por entonces de una credibilidad importante en la alta cultura. Su paridad en el imaginario nacional se evidenciaba no sólo en la autoridad que llegaron a detentar individualmente, sino también en la existencia de una Academia conjunta, donde historiadores y letrados definían la forma de aproximarse al pasado y de enseñar sus hallazgos en las aulas de clases. Por ello, no podría afirmarse que el debate entre positivismo y nacionalismo se basaba en la disciplina del sujeto enunciador, sino en la jerarquización de los acontecimientos.

Más que definir una metodología, la discusión se centró en qué acontecimientos pasados -0 , al menos, qué tipo de acontecimientos- resultarían más útiles para reforzar los lineamientos del campo cultural del país mientras, paralelamente, se formulaban una serie de estrategias dirigidas a solidificar la presencia de un intelectual varón y mestizo como garante de la inscripción del territorio nacional en la modernidad latinoamericana. Las dos posturas en pugna tenían como objetivo común la construcción de un pasado cohesionado, en cuya lectura se encontrara la justificación necesaria del perfil del intelectual regente en los años cincuenta. Quizás uno de los textos que mejor dé cuenta de ello sea "La conciencia del presente" (1955), de José Luis Salcedo Bastardo, donde se indica:

Vive el universo el dilema trágico de las ideologías avasallantes. En su historia puede hallar Venezuela cuanto requiera para cimentar la posición más conforme a su interés y su deber. La sustancia para robustecer su tradición de independencia y paz.

A la desarticulante división del pasado nacional defendida por la Escuela Tradicional, oponemos la unidad del proceso histórico. En más de una ocasión hemos proclamado mirar la historia como visión orgánica de continuidad y con sentido pleno de unidad. Venezuela no es producto de un ímpetu egoísta, ni resultado de la acción excluyente de un grupo selecto ni de una hora estela. La Patria, para nosotros, es una verdad dinámica en la cual se conjuga la acción de todos sus hijos y de todos los instantes de su vivir (Salcedo Bastardo, 1955: 4) 
En esta breve referencia se establece la necesidad de construir un sujeto colectivo que, si bien no luce a simple vista como jerarquizado, goza de un perfil tan claro que acaba por convertirse en una categoría cerrada. Es decir, Salcedo Bastardo habla de un "todos" que construye la nación; sin embargo, a lo largo de su artículo propone un presente histórico homogéneo, que impide la singularización de los acontecimientos. Por ello, resultaría imposible analizar bajo este nuevo "paradigma conciliador" los acontecimientos concernientes a aquellos sujetos que no han alcanzado del todo la noción de ciudadanía.

Paradójicamente, estos esfuerzos por prescribir la escritura del pasado generaron una serie de grietas a través de las cuales se pudieron escuchar voces divergentes. Se trataba de subjetividades ajenas a esa colectividad perfilada por voces como las de Nucete Sardi y Salcedo Bastardo que, dada su rareza, demandaban un pasado alternativo. De hecho, cuando en "La conciencia del presente" el autor reafirma de forma explícita la capacidad de selección, análisis y reconstrucción del historiador, al tiempo que le atribuye a este sujeto la capacidad de tomar alguna información en torno al pasado y "sin remordimientos [...] relegar[la] al rincón de los desechos" (Nucete Sardi, 1955: 4), está sugiriendo la existencia de autores y textualidades empeñados en valorar acontecimientos "no relevantes" para esa plataforma llamada "Historia nacional", artefactos cuyo estudio puede resultar muy útil si se pretende comprender el manejo de la rememoración en la Venezuela de los cincuenta ${ }^{1}$.

En este grupo se podrían inscribir los textos Memorias de una loca (1955), de Conny Méndez; La mujer del caudillo (1952), de Nery Russo; Otoniel (1955), de Inés Guzmán Arias; Bruja del Ávila, de Alecia Marciano (1957); o Memorias disparatadas (fechada en 1954, pero publicada en 1959), de Cristina Ferrero. Una gama de libros de memorias, testimonios y novelas históricas escritas por mujeres venezolanas entre 1952 y 1958, donde se reeditan algunos eventos pasados desde la distorsión de la contemporaneidad y donde, por medio de intertextualidades, juegos

\footnotetext{
${ }^{1}$ Aunque este trabajo se circunscribe al período dictatorial de Marcos Pérez Jiménez (19521958), no se puede dejar de lado la importancia que ha tenido, desde el siglo XIX, la relación entre Historia y literatura en Venezuela. Luz Marina Rivas, en su libro La novela intrahistórica (2004) expone: "Una gran cantidad de novelas históricas que han roto con los pactos de la verdad, que cuestionan irreverentemente una noción unívoca de lo que sucedió, han producido el efecto de una sacudida en el trabajo teórico de los críticos literarios quienes han tenido que enfrentarse a ficciones de la historia muy distintas a las que George Lukács había llamado con ese nombre en su ya clásico estudio sobre este particular sub-tipo de novela producido desde el siglo XVIII en Europa". Más adelante, añade: "la literatura venezolana tiene una larga tradición de matrimonio con la historia desde el siglo XIX" (Rivas, 2004: 16). Es decir, la autora recuerda la necesidad de evocar y organizar el pasado que ha marcado la producción discursiva en el país, al tiempo que insinúa el carácter irreverente de estas prácticas rememorativas.
} 
de anacronismos, parodias y fragmentariedades, la tergiversación de la Historia se torna una noción indispensable para adquirir un "yo".

A este respecto, un texto que resulta sumamente importante por su complejidad, su ambigüedad y las paradojas que contiene, es la novela Hossein (1955), de Inés Guzmán Arias. Una obra donde la autora parte de la celebración de una fiesta hindú llamada "Hossein" en la isla de Trinidad -tildada de "extravagante" y exótica, por la voz narrativa-, para construir una alianza con otras subalternidades: descendientes de la India de clase social baja, "indianos" (hindúes nacidos en Trinidad) y personajes desplazados fuera de su tierra natal. Al mismo tiempo, se plantea el retorno a un origen que aparentemente se ha venido olvidando a medida que otras creencias y religiones avanzan.

El libro Hossein, subtitulado "novela histórica", se inscribe dentro de un imaginario que le resulta a la autora propio y ajeno al mismo tiempo, lo que le permite adscribirse a una genealogía de la recuperación del pasado, sin desprenderse del todo de un perfil de mujer intelectual que le era impuesto desde el aparato del Estado. En este sentido, al leer la obra emerge la necesidad de preguntarse: ¿Hossein parte de una idea de nación como referente identitario?, ya que el personaje principal se construye a partir de hechos que le son narrados ¿Qué papel juega la memoria en la adquisición del mismo? ¿Se trata de otra lectura alternativa de la Historia o tan sólo de una propuesta de reorganización? ¿En qué términos se propone la participación femenina en este tipo de relato? ¿Cómo se incluye la mujer y las otras subalternidades dentro de la Historia?

Sin duda, constituyen un punto de partida muy elocuente las primeras páginas del texto, empleadas por Inés Guzmán Arias para ubicarse en el campo cultural venezolano. Tras referir las obras que ha publicado la autora y las que tiene en preparación, se enumeran veinticuatro reconocimientos nacionales e internacionales recibidos por ella en los años anteriores, entre los que se cuentan algunos logros tan ajenos a la escritura narrativa como: la "credencial de delegada de la "Fraternidad Espiritual Latinoamericana', Buenos Aires, 1937" (Guzmán Arias, 1955: 7); el "Diploma de socio activo de la 'Sociedad Filarmónica de Sucre', otorgado en Sucre (Bolivia). 1938" (Guzmán Arias, 1955: 7); o el "Diploma de honor y mérito otorgado por el Instituto Técnico Industrial de Río de Janeiro (Brasil). 1954" (Guzmán Arias, 1955: 9).

Del mismo modo, una vez que ha finalizado la novela en la página 145, aparecen cincuenta y cuatro páginas más, donde se pueden leer comentarios -en su mayoría inéditos y/o extraídos de correspondencia privada- sobre Inés Guzmán Arias y su escritura. Acotaciones provenientes de distintos países latinoamericanos y destinadas a resaltar una trayectoria imposible de rastrear en los diarios venezolanos del la época, donde otras autoras como Gloria Stolk, Lucila Palacios, Juana de Ávila o la misma Conny Méndez mantenían sus columnas o eran referidas como autoras importantes de la literatura nacional. La presencia de Guzmán Arias ni siquiera se puede determinar en manuales como ¿Quiénes narran y cuentan en Venezuela? 
(1958), de Ángel Mancera Galletti, donde sí se registraba la escritura de sus contemporáneas.

Por ello, a diferencia de lo que había sido hasta entonces la narrativa de las escritoras venezolanas más o menos consolidadas para la década de los cincuenta del siglo XX, se puede afirmar que, al comienzo de Hossein, la escritora no se disculpa por estar invadiendo el territorio de la alta cultura -quizás, precisamente, porque nunca consigue hacerlo del todo-, sino que reitera su condición de intelectual internacionalmente reconocida y, por lo tanto, su legitimidad para reconstruir el pasado desde una mirada letrada. Entonces, no resulta del todo sorprendente que el primer personaje femenino que aparezca en el texto sea una evidente ficcionalización de la autora, quien se muestra como traductora o transcriptora de los hechos.

La voz de esta mujer narra y describe a cabalidad la procesión solemne llamada "Hossein", una celebración de "otra cultura" que resulta un tanto incomprensible para los nativos y los extranjeros. Este procedimiento resulta por demás interesante, pues visto a la luz de la primera presentación de la autora podría consistir en una reterritorialización de la dicotomía civilización/barbarie. Ella, desde su mirada letrada, trata de comprender $\mathrm{y}$, sobre todo, de explicar aquella práctica improductiva $\mathrm{y}$, desde una mirada que hasta ese momento se ha mostrado como irracional, un tanto absurda. Quizás lo más interesante a este respecto consiste en la pretensión manifiesta en la voz narrativa, pero desde cualquier punto de vista atribuible a la autora- de establecer un mapa subjetivo del entorno, de un territorio donde no nació, no se formó, ni ha habitado por demasiados años. En otras palabras, resulta interesante el deseo de "colonización" expresado por este personaje femenino, quien recuerda desde la enunciación del mismo ese perfil común a los protagonistas mesiánicos de la escritura regionalista. Así pues, desde las páginas iniciales del texto se puede leer:

[Los anglohindúes o indianos] son admirables por su constancia en el trabajo; son admirables por la fortaleza con la que se someten a su herencia atávica, observando su religión y sus creencias aun viviendo en diario contacto con personas y familias civilizadas. La raza hindú puede decirse forma el palpitante corazón de la británica isla de Trinidad; la parte inferior del pueblo está formada por la raza negra o descendientes de Can, pero éstos no son tan trabajadores y mucho menos tan inteligentes que [sic] los primeros. Los indianos ricos poseen magníficos edificios, hoteles y granjas, y algunos se doctoran en Inglaterra en distintos ramos del saber (Guzmán Arias, 1955: 22)

En este breve fragmento se pueden distinguir al menos dos operaciones básicas dirigidas a crear la organización territorial necesaria para iniciar ese proceso de modernización que proponían tanto el proyecto desarrollista de Marcos Pérez Jiménez como el discurso regionalista, desplegado hasta los años treinta, en el continente. Por una parte se presenta la disección, clasificación y jerarquización de los habi- 
tantes; por la otra, se introduce una marca determinista -que en este caso es el origen étnico- para hacer reconocible cada subgrupo.

Esta representación de los trinitarios -0 , mejor dicho, de quienes circulan por Trinidad- se realiza sin construir, ni tan siquiera contemplar, la existencia de un sujeto trascendente, con costumbres, discursos y creencias propios, pues -aún cuando se reconoce en los indianos la posibilidad de formarse en una institución universitaria- estos personajes son mostrados como un colectivo homogéneo y previsible. Del mismo modo, cada tipología es edificada a la luz de un pensamiento ético con pretensiones de universalidad.

La experiencia de explorar la isla que lleva a cabo el personaje coincide, además, con un dato biográfico de Inés Guzmán Arias, quien nació en Cumaná pero residió por varios años en Puerto España. Personaje y autora, a partir del enfrentamiento con diversas religiones reconocidas en la isla, recalcan en todo momento su adherencia a la religión católica. Por ello resulta muy elocuente que "la narradora" elija circular por ese territorio y, a la manera de los intelectuales del regionalismo, comience a elaborar un relato didáctico. Un discurso pedagógico que haga constante alusión a la memoria/recuerdo y, con ello, se adhiera a un presente que reitera notablemente el pasado, y en el cual se le atribuye gran importancia a las descripciones detalladas de paisajes naturales y/o a la geografia de las regiones.

De este modo, además, la autora deja entrever su condición de sujeto del saber, aunque en el proceso se distancie brevemente del paradigma de la novela de la tierra que había refrendado en las páginas iniciales del texto. La primera voz narrativa de Hossein, si bien se autoafirma como más racional que su entorno, no "relata" como consecuencia de esta condición y, aunque se erige como el único sujeto de la escritura, sugiere que otras identidades pudieran recibir alguna formación académica. Esta ambigüedad sirve para establecer que la capacidad organizadora del personaje no se deriva de ser "una mujer letrada" sino, paradójicamente, de su marginalidad, de la posibilidad de presenciar a los otros sin ser parte de la acción. Esta voz se sabe "testigo" y, desde su diferencia, recupera historias olvidadas o dejadas de lado para autorrepresentarse, en ocasiones acudiendo a la autoironía.

Ahora bien, en la misma medida en que este personaje femenino se edifica como colector y reconstructor del pasado, su participación activa en el texto se va diluyendo. Se encuentra, entones, con la figura del padre Joseph quien, a su vez, va a relatar en medio de un diálogo la vida de un hombre - no ya de un rito- llamado "Hossein". En este encuentro se producen varios desplazamientos interesantes. Por una parte, la centralidad de "la testigo" le va a permitir seleccionar la oralidad como origen del saber, pues ella está autorizada a desestabilizar las fuentes reconocidas por la historiografía. En segundo término, se deja claro que este nuevo emisor del discurso tampoco ha adquirido la información que relata tras un proceso de formación académica, ni tan siquiera de la observación, como fue el caso de la narradora inicial. 
Por el contrario, este personaje masculino se ha formado desde la intersubjetividad o, lo que es lo mismo, desde la experiencia de haber "conocido" y/o haberse involucrado afectivamente con el hombre de quien habla. Ni siquiera encarna a un ingeniero -como correspondía al ethos desarrollista vigente en la sociedad venezolana de la década de los cincuenta-, a un varón letrado -como hubiera ocurrido en el regionalismo-, ni a un médico -como hubiera podido esperarse de una mujer intelectual, a quien se le exigía cierto apego al imaginario decimonónico-, sino de:

[e]l sacerdote que es parte interesante de esta histórica narración, sólo falta decir que este humilde capellán de altar era un venerable anciano de unos 60 años de edad, poco más o menos alto, delgado, de mirada límpida, casi angelical y triste. Hablaba pausadamente con voz dulce y franciscana; tenía nariz fina, boca pequeña, labios delgados, prontos siempre a la sonrisa atrayente. Todo en él atraía e inspiraba veneración. Su color de canela hacía conocer su raza, pero era imposible sondear su origen, tal era el respeto que inspiraba e imponía. Su frente estaba siempre inclinada, sus manos juntas en actitud de estar absorto en una oración ante el altar. Así era, más o menos, el venerable "Padre Joseph", como todos le llamaban (Guzmán Arias, 1955: 25).

Es obvio que la organizadora del texto le ha atribuido a este personaje masculino una posición marginal, lo ha ubicado en un espacio de subordinación aún mayor al que ella -como mujer letrada, que mira y transcribe- podría ocupar en el imaginario venezolano. Un gesto que, al contrastarse con la larga presentación de sí misma realizada Inés Guzmán Arias en las primeras páginas del libro, adquiere nuevos sentidos. En este encuentro del sacerdote anciano con la intelectual venezolana, ella "sabría decir" sin "decir que sabe", pues todo lo que relata ha sido afirmado por el padre Joseph quien, a su vez, "dice sin saber", pues su perfil no es compatible con la adquisición de conocimientos positivos como los que se demandaban a los constructores de la Historia ${ }^{2}$ (Ludmer, 1984).

En otras palabras, desde el comienzo de la novela, la vía de acceso al conocimiento está dislocada y, como consecuencia de ello, se torna accesible para la subalternidad. Guzmán Arias traza un camino alternativo para conciliar lo femenino -

${ }^{2}$ En su texto, "Las tretas del débil", al hablar de la escritura de Sor Juana Inés de la Cruz, Josefina Ludmer establece: en este doble gesto se combina la aceptación de su lugar subalterno (cerrar el pico las mujeres), y su treta: no decir pero saber, o decir lo contrario de lo que sabe. Esta treta del débil, que aquí separa el campo del decir (la ley del otro) del campo del saber (mi ley) combina, como todas las tácticas de resistencia, sumisión y aceptación del lugar asignado por el otro, con antagonismo y enfrentamiento, retiro de colaboración (Ludmer, 1984: 41). En el caso que nos ocupa este gesto de construir a un personaje que a su vez construye a otro en un espacio-tiempo remoto, descargaría de peligrosidad el gesto organizador y el proyecto territorial de Inés Guzmán Arias. 
que en este caso es tan solo un rasgo de identidad más- y lo empírico -que define al sacerdote- con la figura del intelectual, como si aceptara que su lugar para hacer política es el de la recepción y no el de la emisión, aunque -y esto es quizás lo más importante- en este acatamiento aparente a la racionalidad y a los roles genéricos que se definen a partir de la misma, la figura del narrador se ubique en un punto poco convencional.

El padre Joseph se sitúa "frente" al conocimiento histórico, presenta detalles y pormenores de sus personajes quienes, a la vez, se tornan objetos de introspección y de análisis. Su discurso parte del recuerdo, de la rememoración de acontecimientos lejanos que -como se evidencia hacia el final de la obra-constituyen su propia experiencia. Del mismo modo, "la transcriptora" habla acerca de sí misma como una lectora sin voz, que -a la manera de las receptoras del melodrama del siglo XIX - se dedica a registrar el discurso que ha sido construido para ella. Por eso, no es extraño que, en las páginas iniciales, hable de su "obrita" como producto innato de su conocimiento.

En el diálogo entre la narradora y el sacerdote, como se comentó anteriormente, el término "Hossein" ya no sólo va a designar el rito pagano, sino también a un hombre. Un sujeto de raza indostánica, nacido en Trinidad, que ha sido llevado por sus padres al Perú cuando es muy pequeño. Poco tiempo después, su madre enferma y muere. Desde temprana edad, este personaje accede a la palabra escrita y se caracteriza por unas ansias inmensas de conocer el mundo, aproximarse a sus antepasados y comprender la religión de sus padres. De hecho, cuando la "mujer que narra" desaparece de la anécdota, Inés Guzmán Arias emplea a este personaje como figura ideal para la autorrepresentación. En una de las primeras intervenciones de Hossein en la novela se puede leer:

No sé por qué, a pesar de mis estudios y del roce social que me une a la mejor sociedad de estas Antillas, no puedo desarraigar de mi alma la religión de mis antepasados, la religión que me enseñaron mis padres. No, jamás podre apartarme de aquellas queridas creencias que mi padre supo sembrar en mi interior; y, lo que es mayor aún, tengo la firme convicción que en mí esta reencarnado mi propio bisabuelo, cuya historia he leído muchas veces y la siento palpitar en mi memoria como un tatuaje de fuego (Guzmán Arias, 1955: 46)

Este episodio evidencia la necesidad de escenificar "La angustia de los orígenes". Ese sentimiento que inicia al personaje central de la novela -junto con el vínculo autofigurativo, a la misma Inés Guzmán Arias- en una travesía épica, sin la cual sería imposible hallar un territorio de anclaje. Para retornar al pasado se utiliza la memoria como método de búsqueda, como vía para acceder al origen o a la esencia primigenia del ser humano. La autora utiliza pues el acto de recordar partiendo de la autoconciencia con el fin de activar la memoria de los lectores. Tanto la experiencia individual de Guzmán Arias, como su experiencia de vivir al "otro" se 
abastecen de la condición humana. Como recuerda Louis Parkinson Zamora en La construcción del pasado, al referir la escritura de Willa Cather:

Su búsqueda de un pasado utilizable la une a los principales escritores de su tiempo, aunque nunca compartió la sospecha moderna de que el pasado americano era débil o no existía. Podríamos considerar esta diferencia en términos que sugiere la crítica feminista. Aquellos que no han poseído una historia -aquí no nos referimos a los americanos, sino a las mujeres- prefieren, naturalmente, recuperar el pasado antes de descartarlo como inadecuado. La recuperación de la historia perdida se vuelve una parte esencial del proceso de liberación, puesto que el pasado que no se analiza opera como destino más que como revelación (Parkinson Zamora, 2004: 48)

En el caso particular de la novela Hossein, la declaración del protagonista funciona como un reconocimiento de su propia subalternidad, que lo obliga a rastrear(se) en la memoria familiar, al tiempo que -manteniendo el juego de ambigüedades inicial- reactiva la centralidad de la voz narrativa, disuelta en su encuentro con el sacerdote. Por contraste con la declaración del personaje Hossein, con la escritura de esta novela, Guzmán Arias guiará al pueblo e intentará instaurar su noción de verdad, de moral y de ética para verificar qué se considera "bueno", "malo", "correcto", "incorrecto", "obligatorio" o "permitido" o, lo que es lo mismo, se mostrará como la voz organizadora del entorno, mientras que el personaje masculino sólo se dejará llevar por un impulso y, en su desplazamiento, no acarreará compañía, ni congregación.

Del mismo modo, en la diégesis del texto, la principal voz femenina corresponderá a un personaje con sus arraigos y filiaciones claras, mientras que Hossein será mostrado como un nómade, que nunca podría inscribirse en algún territorio nacional. La presencia de ambos, más allá del gesto de sometimiento inicial, permitirá romper con algunos esencialismos instituidos por la Historia en la década de los cincuenta, que ubicaban al varón letrado en el centro de la nación. Incluso, podría decirse que al pensar la dupla origen/poder, Guzmán Arias entiende el género no sólo como elemento constitutivo de las relaciones sociales basadas en las diferencias de sexo, ni como forma primaria de relaciones significantes de poder, sino como negociación entre ambas (Scott, 2000).

Pese a ello, es innegable la creación de nuevas alteridades, de sujetos desalojados a partir de la asunción de la testigo como centro. La construcción étnica, por ejemplo, va a resultar muy útil para este fin. En esta novela, el uso mismo del término "raza" surgirá como un intento histórico de clasificación de los seres humanos a partir de características biológicas visibles; no obstante, es importante recordar que, ya para 1955, el momento de publicación de Hossein, los científicos evolucionistas habían rechazado esta conceptualización. Tanto para la biología como para la antropología, desde la primera mitad del siglo XX la especie humana pertenecía a una única raza, que se dividía en diferentes "etnias", una categoría mucho menos 
taxativa, que estaba basada en las diferencias culturales, lenguaje y religión. De esta manera, al hablar de la "raza india", la autora satura tanto el discurso positivista de la época como el intento de europeización de Venezuela, hasta el extremo de desacreditar todo el sistema de pensamiento. Basta con recordar algunos episodios en los que Hossein conversa con un sacerdote católico y, en medio del intercambio, Oriente y Occidente entran en debate:

\begin{abstract}
Esa creencia de tus antepasados, que ustedes llaman "religión" no avanza. Hace ya muchos siglos está estancada, sin progreso alguno; corresponde a lo pasado; hoy todo aspira a mejorar, a buscar algo nuevo para legarlo a las nuevas generaciones... Hoy vivimos en un siglo, de adelantos fantásticos, que dejan satisfechos y asombrados a los más exigentes. Todo ha evolucionado, ha mejorado, hasta el extremo de asombrar a nuestra época, ofreciendo la maravilla de dar en pocos días una completa vuelta al mundo; ya podemos ir de visita y almorzar en Paris, y sin rigurosa despedida venir a cenar y a dormir a Londres; y de aquí, como quien sale de compras, irse a España al día siguiente, y así, sucesivamente, todo, completamente todo, ha mejorado y es novedad (Guzmán Arias, 1955: 127-128)
\end{abstract}

En este fragmento salta a la vista un intento de recuperar otra dicotomía modernidad/tradición que, a su vez, refrendaba la polarización centro/periferia en el proyecto nacional perezjimenista. Las nociones de movilidad y progreso, demandadas al pensamiento masculino, se distancian en un gesto determinista de esta individualidad, cuyo origen incierto le permite transitar por diversos espacios identitarios. Para la mirada letrada no es demasiado diferente "ser mujer" que "ser mestizo", de la misma manera que Perú o la India se tornan territorios igualmente excéntricos, con lo cual la autofiguración de una mujer letrada en un personaje masculino -pero, dada su extranjería, ajeno a lo "mejorado y la novedad"- no resulta del todo transgresora.

Al mismo tiempo, dentro de la dilucidación sobre creencias religiosas antiguas, se apela directamente a los lectores para cuestionar la tradición musulmana, hindú y mahometana. Se trata de una especie de digresión que cierra con el apoyo al catolicismo como única "verdad". Es decir, desde su propia voz autoral, Inés Guzmán Arias -al menos en apariencia- apoya la modelización del sujeto femenino por medio de imágenes religiosas como la virgen del Valle o la virgen de Coromoto ${ }^{3}$, al tiempo que acata las imágenes católicas como modelos conductuales a seguir.

${ }^{3}$ Dice Felícitas López Portillo, en El perezjimenismo: génesis de las dictaduras desarrollistas (1986), que: Dentro de la ideología ensalzadora de lo castrense y el culto a los héroes, se instituyó la Semana de la Patria durante los primeros días del mes de julio, en ocasión de conmemorarse la firma del Acta de Declaración de la Independencia, efectuada el 5 de julio de 1811 [...] Para dar una idea de lo maratónicas que resultaban estas festividades, basta 
Paradójicamente, esta sumisión a cada uno de los discursos excluyentes en su entera literalidad genera una plataforma colectiva, donde el no católico, el no varón y el no occidental tienden una serie de puentes que los unen y les permiten reconocerse como un colectivo poseedor de una Historia común. Lo más interesante a este respecto es que la ética cristiana, a propósito de ello, va a ser resemantizada y utilizada como malla de contención de todas estas identidades, cuya interacción determina una mirada alternativa sobre el presente continental.

En otras palabras, el acatamiento de los estereotipos va a desembocar en una mescolanza de perfiles sociales y sistemas de creencias que, a su vez, conseguirá desplazar cualquier gesto prescriptivo. Una vez que el personaje Hossein se ha formado académicamente, decide ir tras su destino en la India y convertirse en hipnotista. Entonces, la voz narrativa señala:

el recinto [donde Hossein atendía sus consultas] se hizo muy pronto insuficiente para contener la cantidad de personas que deseaban asistir a las sesiones, y nuestro amigo, sintiéndose orgulloso de su éxito, quiso ocupar un soberbio palacio desalquilado, el cual había admirado extraordinariamente durante sus largos paseos, algo distante de la ciudad. Habiéndole llamado poderosamente la atención el abandono en que se le tenía, al preguntar la razón, le explicaron que debido a las leyendas que le atribuían, era completamente imposible habitarlo; en él ocurrían apariciones fantásticas, que solían presentarse en los altos muros [...] Hossein se mostró complacido y escuchó aquellas leyendas como algo muy interesante, riéndose de muy buena gana, y desafiando aquellas leyendas quedó instalado en el "palacio maldito" (Guzmán Arias, 1955: 53)

Hay una serie de alusiones en este fragmento que revelan la voluntad de la autora de mostrar el hecho literario como parte de una máquina discursiva. Sin duda, las referencias a la casa misteriosa y al hipnotismo, parecieran tomadas de medios impresos venezolanos como El Nacional o la revista Elite que, en los años cincuenta, reprodujeron textos con títulos como "La misteriosa India", "La influencia de Ghandi en América", "Sobre los gurúes de la India", "La India milenaria", "Delhi: la estrella musulmana de la India" o "De tierras misteriosas y remotas", en sus pá-

señalar que en la Semana de la Patria correspondiente a 1956, desfilaron 156 bandas militares y 175 institutos en total, así como diversas organizaciones deportivas.

El gobierno contó con la bendición de la Iglesia -en una ocasión la Virgen de Coromoto, la máxima patrona del pueblo venezolano, y la de El Valle pasearon por la calles de Caracas en tanques militares-. El Concejo Municipal las declaró "visitantes insignes", mientras que el régimen las nombraba "patronas de la semana de la Patria" (López Portillo, 1986: 75-76). Es decir, en el imaginario de la refundación nacional, el Estado perezjimenista modelaba a los sujetos masculinos desde el ethos castrense y al femenino desde el pensamiento católico. 
ginas, para definir - desde una mirada externa- una configuración de esos espacios remotos que permitiera pensar la nación venezolana como parte del "mundo civilizado". Concretamente, en el artículo "Visión de la India", publicado en el año 1955, en el No 4.287 del diario El Nacional, se afirma:

De lo remoto de aquellas tierras, de lo acumulado por los siglos esperamos en nosotros, por reacción, ideas muy nuevas y terminantes, mas para lograrse esto debe combinarse un estudio de las partes donde no prive ni el muy extático pensamiento hindú en la actitud de mirarse el ombligo, ni la desesperación interminable de la mecanización occidental de la vida que ahorra un tiempo sin saber después en qué emplearlo. La antigüedad enseña y alecciona, pero es supersticiosa. La vida sin historia que ahora generalmente nos acompaña, demuestra en sí una filosofía basada en la preponderancia del instante. Si no somos dueños de lo remoto -hasta carecemos de lo remoto- si no obedecemos a una tradición tan vasta, eso nos permite manejar el minuto del suceso con soltura (Henríquez Chalbaud, 1955: 4)

Es claro el deseo de Guzmán Arias de construir un personaje que represente el perfil esbozado, entre otros articulistas, por Henríquez Chalbaud; sin embargo, no deja de ser interesante que este juego intertextual sirva de marco para la reactivación de la pugna razón/pasión. Sobre todo, si se tiene en cuenta que la noción de verosimilitud del discurso era entendida en la literatura venezolana canonizada para los años cincuenta, como una derivación de la racionalidad en tanto forma legítima de conocimiento. Resulta curioso que Guzmán Arias trate de elaborar un texto verosímil empleando referencias a discursos letrados previos, cuyas dicotomías implícitas, aunque resultan inevitables, terminan por ser revertidas.

Es decir, si bien en los textos aparecidos en prensa se habla de la India, siempre se presenta este país como un espacio remoto en tiempo y espacio, que debía observarse con admiración y distancia. A diferencia de ello, Guzmán Arias construye un personaje que, aunque trabaja como hipnotista, se muestra escéptico ante las creencias de su entorno. Con ello, acerca al héroe a su cotidianidad y a las miradas que prescribían la lectura de la India. Podría afirmarse entonces que las motivaciones para crear la novela Hossein distancian esta obra del proceso argumentativo de Henríquez. De este modo, la lejanía que establece el personaje con la creencia popular en torno a la casa no viene dada por el privilegio de la racionalidad sino por el desconocimiento del pasado, lo que -a la vez- le permite a la autora valorar el conocimiento metafísico, pasional o sentimental. Un planteamiento que se reafirmará cuando, a lo largo del texto, Hossein acabe atrapado en una serie de hechos inexplicables, acontecidos en el interior del palacio.

A ello se suma, además, que dentro del recinto misterioso se construyen los dos únicos personajes femeninos que interactúan con Hossein. Dos mujeres que no parecen tener cabida en la Venezuela de los cincuenta. Al hablar de la primera de ellas, la voz narrativa señala: 
Jovand, al entrar en su lujosa mansión, se dirigió a su alcoba, se desprendió del manto que la cubría y, con los ojos bañados en lágrimas, se acercó a un ídolo o estatuilla de oro que representaba la imagen de Vichnú, y, besándola ardorosamente, dijo, como si musitase una oración - ¡Oh, Alá!, representante de nuestro supremo creador del universo, protector de los seres, no permitas que Hossein pertenezca a lo que me está vedado amar. Haz realidad mi esperanza, que ha sido creada por ti en mi corazón (Guzmán Arias, 1955: 89)

Esta transposición de Visnú, la deidad hinduista, y Alá, el dios musulmán, en el discurso de un sujeto femenino, se presta a múltiples interpretaciones. Por una parte, deja al descubierto esta suerte de comunión de las subalternidades propuesta por Inés Guzmán Arias a lo largo de todo el texto. Según Jovand, no hay límites que separen los discursos no cristianos. En segundo término, esta súplica abre la posibilidad de concebir a una mujer no católica en un pasado reciente, un territorio espaciotemporal no demasiado lejano al que la autora habitaba. Por último, este borramiento del dualismo que definiría las identidades y las alteridades religiosas negaría cualquier justificación posible de la violencia epistémica que negaba el valor documental del discurso femenino.

Resulta interesante, además, que Guzmán Arias atribuya este comentario a una mujer que, como tal, pudiera haberlo enunciado por desconocimiento y no porque pretendiera diluir los límites de las identidades. De hecho, tanto Jovand -la mujer hindú-, como Danifa -la mujer occidental-, desempeñan un papel secundario en la trama, que roza el límite de lo decorativo. Jovand es una hindú muy hermosa, de clase alta y linaje distinguido, elegida como novia de Hossein. Ella idealiza el matrimonio y la vida de pareja pero también encarna a la mujer envidiosa, celosa y ávida de venganza porque su amor no es correspondido; mientras, Danifa es establecida como el símbolo de la belleza real y, por su cercanía al fenotipo occidental, llama la atención de Hossein desde el primer momento. Por oposición a Jovand, Danifa representa el arquetipo de la virgen.

En un primer momento, podría pensarse que ninguna de estas dos mujeres goza del capital simbólico suficiente para que sus comentarios puedan afectar la visión distante o descalificadora que el desarrollismo dirigía al pensamiento oriental; sin embargo, el hecho de que estos estereotipos femeninos decimonónicos que habían sido recuperados por la prensa venezolana de los cincuenta con total libertad sean inscritos en medio de una llamada "novela histórica" y que, en el marco de la ficción, se les permita reflexionar en torno a la existencia o inexistencia de los límites de las religiones no católicas, traslucen cierta puesta en cuestión del binomio masculinidad/feminidad asentado en el afán de modernización del pensamiento perezjimenista.

Es decir, si bien Guzmán Arias reproduce a dos tipologías femeninas abiertamente aceptadas por los medios de comunicación social y hace que una de ellas confunda de forma arbitraria el hinduismo con el islamismo en un gesto que pare- 
ciera reafirmar el mapa subjetivo que proponía el Estado venezolano para la década de los cincuenta, lo hace en el marco de una llamada "novela histórica", desde una posición a veces central en el campo cultural del país, con lo cual no sólo desdice el carácter conciliador de los ejercicios de rememoración que autores como Nucete Sardi o Salcedo Bastardo promovían sino que, además, distancia su contemporaneidad de la existencia de estas dos mujeres.

Ahora bien, con la presentación de Danifa la racialización del pensamiento positivista entra nuevamente en el debate y aunque reafirma la superioridad occidental, al menos en apariencia, a medida que avanza el texto va contaminando la dicotomía. Por ejemplo, cuando el personaje es aludido por primera vez en el texto, la voz narrativa asevera:

cuando por entre todos los presentes se acercó una mujer joven, deslumbradoramente bella, hermosa como un sol, que sin proponérselo, eclipsó la belleza de todas las damas presentes y llamó poderosamente la atención de los hombres, despertando verdadera admiración. En aquel instante quedaron todos extasiados ante aquella aparición, que les pareció sobrenatural, así lo creyeron los hindúes; era casi una niña, apenas parecía contar quince años, traía la brillante cabellera peinada sin arte, pero graciosamente recogida, que le daba parecido a las estatuas griegas; en su traje, azul claro, lucía, cerca del alto cuello, una rosa entreabriendo; una leve sonrisa iluminaba su rostro, de blancura admirable; sus ojos, azules como los lagos donde palpita el eterno romance de los bosques y la aves... Todo en ella hacía resaltar la raza europea a la que pertenecía (Guzmán Arias, 1955: 71)

Sin duda, resulta llamativo el nuevo proceso de inversión que se lleva a cabo en el texto, pues si bien pareciera que este pasaje iba dirigido a exaltar la superioridad occidental frente a un oriente caduco, la voz narrativa asume una posición cercana a la del cronista, quien al arribar a un espacio extraño, se lo apropia y lo territorializa. La voz - que ha sido desplazada del sacerdote a la "traductora"- se encarga de nombrar la alteridad, en gesto que inaugura a esa figura femenina encarnada en una mujer occidental, pero tan imposible de pensar en la cotidianidad de la autora que, en primer lugar, es asumida como un fantasma y, finalmente, muere de manera inexplicable ${ }^{4}$.

${ }^{4}$ Guzmán Arias, en este movimiento, recuerda a Michel De Certeau, cuando afirma: "Americo Vespucci el Descubridor llega del mar. De pie, y revestido con coraza, como cruzado, lleva las armas europeas del sentido y tiene detrás de sí los navíos que traerán al Occidente los tesoros de un paraíso. Frente a él, la india América, mujer acostada, desnuda, presencia innominada de la diferencia, cuerpo que despierta en un espacio de vegetaciones y animales exóticos [...] Va a hacer de ella un cuerpo historiado -el blasón- de sus trabajos y de sus fantasmas. Ella será América "latina". 
En esta novela, la voz usurpadora mitifica a la mujer occidental hasta convertirla en un símbolo, en un elemento mucho menos vital y cotidiano que el del primer personaje femenino que narra. Obviamente, se trata de otra estrategia de definición del "yo" empleada por Inés Guzmán Arias, pues la edificación de este constructo mítico en el mundo occidental, sin cuestionar del todo las dicotomías que subyacen a su construcción, humaniza a la mujer latinoamericana, quien circulará libremente por el espacio, cambiando libremente de posición enunciativa. Tanto el arquetipo de la prostituta oriental, como el de la virgen occidental están condenados a desaparecer, por contraste con la intelectual que sobrevive para registrar esta modificación.

En este gesto, además, se asoma una problematización metahistórica. La voz narrativa parece afirmar que sí hay cabida en el marco de la "novela histórica" para personajes estereotípicamente femeninos, aunque la representación de los mismos sólo tenga como finalidad exponer su carácter mítico y atemporal. Ello, aunado al origen de la voz narrativa, sirve para tematizar el deseo de desacralización de la disciplina histórica que define esta escritura. Un gesto indispensable para poder inscribir subjetividades alternativas -y no meros tipos sociales- en la memoria colectiva.

Ahora bien, resulta sumamente curioso que -en medio de las tensiones de afirmación y negación que se proponen en la novela-, la autora decida que la solución de su personaje ante la pérdida de las mujeres esenciales no esté en buscar un par social humanizado, sino en el sistema mítico por excelencia, la religión ¿cómo podría entenderse entonces este desplazamiento? ¿Cómo un acatamiento por parte de la autora de la tendencia del Estado perezjimenista a leer a la mujer desde el pensamiento mágico? ¿Cómo una denuncia de la imposibilidad masculina a comprender a la mujer más allá de las representaciones divinas?

Una pista interesante para leer este fenómeno en toda su complejidad se presenta en la novela, cuando - tras la muerte de Danifa y su encuentro con un Obispo- el protagonista lamenta su soledad. Cuando afirma "todos mis afectos están perdidos, siento el alma vacía [...] ni siquiera tengo a mi madre" (126), el clérigo responde:

\begin{abstract}
¡Sí, tienes madre!- interrumpió el santo levita-; no debes olvidarlo nunca, nunca. Solicita su ayuda y la encontrarás. Ahora mismo iremos a la capilla, te mostraré la imagen de María al pie de la Cruz en el preciso momento de recibir la entrega simbólica, cuando Jesús le dijo: "Mujer, mira a tu hijo". Siempre te veo en el grupo de enfermos que asisten a los santos oficios, pero nunca me has a acompa-
\end{abstract}

\footnotetext{
Esta imagen erótica y guerrera tiene un valor casi mítico, pues representa el comienzo de un nuevo funcionamiento occidental de la escritura" (De Certeau, 1993: 11). En el caso particular de Hossein, la visión externa se estaría originando en una isla del Caribe, de la voz de una mujer extranjera, y estaría siendo dirigida hacia la representación iconográfica de un mundo, en teoría, racional.
} 
ñado a rezar; ¿me acompañarás esta tarde? ¿Rezarás conmigo? (Guzmán Arias, 1955: 126)

Quizás el primer elemento que se debe tener en cuenta es que, si bien se trata de dos personajes masculinos que, de algún modo, sacralizan y desvirtúan a la mujer de su contemporaneidad - pues cuando escriben su historia, se apropian de su imagen, la dejan sin voz y le adjudican, al mismo tiempo, un sentido utilitario- tanto el sacerdote como el expatriado son construidos -aunque bajo la treta de la traducción- por una voz femenina. Con lo cual, el lenguaje masculino es llevado hasta el extremo por su afectación y sus residuos de oralidad. Llama la atención, entonces, que la única voz que conserve su tono analítico sea el de la mujer que recoge la anécdota, que -además- no se dedicará a justificar su presencia, sino a reducir la existencia de las mujeres arquetípicas a la fábula tejida en el diálogo.

El apego a la religión católica que ha mostrado hasta este momento Inés Guzmán Arias comienza a perder autenticidad en este episodio, cuya activación niega la posibilidad de existencia de una mujer con el perfil que ella pretendía apropiarse con la publicación de esta novela. Podría hablarse, incluso, de una necesidad de deconstruir, a partir de su representación, este sistema de creencias detentado por el protagonista y, con ello, dejar constancia de un sujeto femenino sin rostro, con movilidad y, sobre todo, con capacidad de estructurar un discurso.

Habría pues una confluencia de miradas. Por una parte, se presentará a la Virgen, objetivada por las miradas masculinas y encargada de cumplir con las funciones mística, cosmogónica, sociológica y pedagógica que les asignan las religiones a las imágenes de mujer (Campbell, 1997) y, por la otra, emergerá una voz femenina cuya función será objetivar a Hossein y al sacerdote, para reducir al texto las presencias arquetípicas y heterogeneizar los sujetos que circulan más allá de la construcción textual.

Esta paradoja adquiere aún mayores significados hacia el final de la novela, cuando se cuenta que Hossein se convirtió al catolicismo, se hizo sacerdote y adquirió el nombre de Joseph. Entonces se añade un epílogo:

Así termina esta novela, que guarda muchas verdades; antes de finalizarla recuerdo la actitud de aquel buen sacerdote, al terminar su narración: inclinó la cabeza, después miró largamente al cielo y de sus ojos apagados por el tiempo y el dolor corrieron muchas lágrimas, que cayeron sobre el recio acantilado que las absorbió con la desesperación de una sed ardiente. ¡Así como absorbía cada gota de las salobres aguas cuando eran bañados sus tostados flancos por las marinas espumas!... (Guzmán Arias, 1955: 145)

Este cierre, que en su enunciado niega nuevamente la condición autoral de la voz narrativa, reactiva los diversos usos que nociones como "verdad", "recuerdo" o "narración" pueden tener en la edificación de una identidad. Del mismo modo, este 
epílogo propone una reflexión acerca de la novela histórica como género, pues si bien Guzmán Arias le ha asignado esta condición a su escritura, con este final la acerca más al relato testimonial. Ante ello, cabría preguntarse por qué habla de verdades guardadas y no exhibidas, o de un personaje completamente determinado por sus emociones como origen del pasado.

Podría hablarse, incluso, de una estrategia para inscribir este discurso en el mapa literario del continente, pues si bien ni los testimonios ni los documentales son parte de la literatura canónica en la América latina de mediados del siglo XX, sus técnicas y su estructura se cuelan bajo el nombre de "novela histórica". Una vez realizado este movimiento, además, la autora atraviesa el texto con la idea de ficción y la noción de narrativa, con lo cual desestabiliza las clasificaciones y los juicios que se empleaban para sistematizar la literatura nacional por entonces.

A este respecto, resulta fundamental tener en cuenta la revisión de la novela histórica latinoamericana realizada en las últimas tres décadas. Los aportes de María Cristina Pons, expuestos en Memorias del olvido. La memoria histórica de fines del siglo XX (1996), abren un espacio interesante de reflexión. Esta investigadora marca una línea que separa la novela histórica europea y latinoamericana anterior a los años setenta del siglo XX y aquella que se editó a partir de los años ochenta. Para hacerlo, indica:

mientras que la novela histórica tradicional supone que la representación ficcional del pasado entraña una correlación entre la representación, hechos y verdad, la novela histórica reciente rompe con tal correlación entre hechos e interpretación. $\mathrm{Y}$ es por ello por lo que, además, parecen requerir que, como parte del contrato de lectura, se reconozcan de manera diferenciada los dos conceptos de Historia que maneja la novela histórica: el de la Historia como acontecer y el de la Historia como construcción narrativa.

La novela histórica latinoamericana plantea así, a fines del siglo XX, que no se puede hablar del concepto de Historia solamente en términos globalizantes o abstracciones conceptuales teóricas o filosóficas (Pons, 1996: 268)

La lectura de textos como Hossein (1955) nos permite entender entonces que, si bien la propuesta de Pons es fácilmente demostrable, no comprende los ejercicios de recuperación del pasado - publicados en el siglo XIX y a comienzos del XX-en toda su extensión y complejidad, sino que se basa únicamente en la revisión de aquellos textos avalados por diversas instancias canonizantes como la prensa, la crítica literaria y la Academia. Así pues, se hace poco menos que obvio el hecho de que las aproximaciones al pasado han sido replanteadas en un momento determinado del siglo XX.

Ahora bien, resulta significativo que, al revisar la novela que aquí nos ocupa, junto con otras tantas que acompañaron su publicación, sea posible identificar -al igual que ocurrirá en ciertos textos canónicos editados en la década de los noventareflexiones metahistóricas, aperturas hacia nuevas interpretaciones de acontecimien- 
tos instituidos como verdades irrefutables y desplazamientos de voces narrativas por las ciencias sociales. Un grupo de recursos que señalan con su presencia una movilización de la novela histórica como género y que, lejos de estar asociada al contexto espaciotemporal de producción, se deriva de la posición subjetiva los autores.

Es decir, si al leer Hossein se toma como asidero la incertidumbre subjetiva que caracterizaba a las mujeres intelectuales en la América latina de mediados de siglo, esa cercanía evidente entre los procedimientos de reconstrucción del pasado empleados por Inés Guzmán Arias y los creadores la nueva novela histórica se constituirá como evidencia. Como una prueba de que -más que una transformación formal-, las ficciones de archivo editadas en el intersiglo XX-XXI se encuentran marcadas por un gesto de politización. Por ello, al igual que ocurría con la narrativa del pasado escrita por mujeres entre 1930 y 1959, estos nuevos textos son creados en/por un sujeto encargado de mostrar la imposibilidad de una reconstrucción neutral.

\section{BIBLIOGRAFÍA}

CAMPBELL, Joseph.

1997 El héroe de las mil caras. México: FCE.

CERTEAU, Michel de.

1993 La escritura de la Historia. México: Universidad Iberoamericana. GUZMÁN ARIAS, Inés.

1955 Hossein. Novela histórica. Caracas: Mediterráneo.

HENRÍQUEZ CHALBAUD, Oscar.

1955 "Visión de la India", El Nacional, n 4.287, Agosto, p. 4 LÓPEZ PORTILLO, Felícitas.

1986 El perezjimenismo: génesis de las dictaduras desarrollistas. México DF: Universidad Nacional Autónoma de México-Dirección General de Publicaciones.

LUDMER, Josefina.

1984 "Las tretas del débil", en González, Patricia E. y Ortega Eliana (eds.). La sartén por el mango. Encuentro de escritoras latinoamericanas. Río Piedras: Huracán.

MANCERA GALLETTI, Ángel.

1958 ¿Quiénes narran y cuentan en Venezuela? Caracas-México: Ediciones Caribe.

NUCETE SARDI, José.

1955 "Historiografía, tendencias y debates", El Nacional, no 4.269, Julio, p. 4.

PARKINSON ZAMORA, Louis.

2004 La construcción del pasado. México DF: FCE. 
PONS, María Cristina.

1996 Memorias del olvido. La memoria histórica de fines del siglo XX. México DF: Siglo XXI Editores.

RIVAS, Luz Marina.

2004 La novela intrahistórica. Mérida-Venezuela: Ediciones El otro/el mismo.

SALCEDO BASTARDO, José Luis.

1955 "La conciencia del presente", El Nacional, no 4.261, Julio, p. 4.

SCOTT, Joan W.

2002 "El género: una categoría útil para el análisis histórico", en Lamas, Marita (comp.). El género. La construcción cultural de la diferencia sexual. México DF: Programa Universitario de Estudios de Género. Universidad Nacional Autónoma de México, pp. 265-302. 